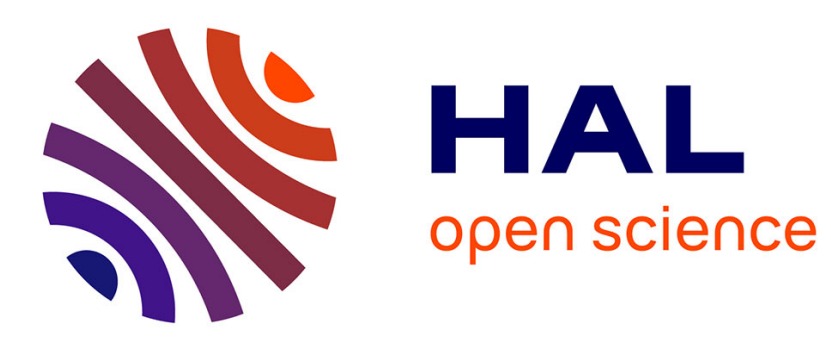

\title{
Ab initio potential energy curve for the neon atom pair and thermophysical properties of the dilute neon gas. I. Neon-neon interatomic potential and rovibrational spectra
}

\author{
Eckhard Vogel, Robert Hellmann, Eckard Bich
}

\section{To cite this version:}

Eckhard Vogel, Robert Hellmann, Eckard Bich. Ab initio potential energy curve for the neon atom pair and thermophysical properties of the dilute neon gas. I. Neon-neon interatomic potential and rovibrational spectra. Molecular Physics, 2008, 106 (01), pp.133-140. 10.1080/00268970701843147. hal-00513171

\section{HAL Id: hal-00513171 \\ https://hal.science/hal-00513171}

Submitted on 1 Sep 2010

HAL is a multi-disciplinary open access archive for the deposit and dissemination of scientific research documents, whether they are published or not. The documents may come from teaching and research institutions in France or abroad, or from public or private research centers.
L'archive ouverte pluridisciplinaire HAL, est destinée au dépôt et à la diffusion de documents scientifiques de niveau recherche, publiés ou non, émanant des établissements d'enseignement et de recherche français ou étrangers, des laboratoires publics ou privés. 


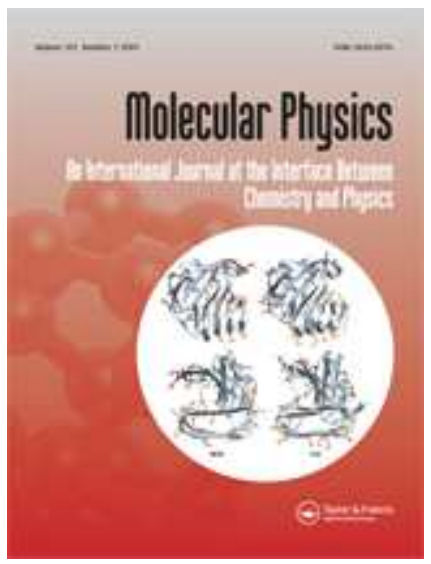

\section{Ab initio potential energy curve for the neon atom pair and thermophysical properties of the dilute neon gas. \\ I. Neon-neon interatomic potential and rovibrational spectra}

\begin{tabular}{|r|l|}
\hline Journal: & Molecular Physics \\
\hline Manuscript ID: & TMPH-2007-0323.R1 \\
\hline Manuscript Type: & Full Paper \\
\hline Author: & 28-Nov-2007 \\
\hline Complete List of Authors: & $\begin{array}{l}\text { Vogel, Eckhard; Universität Rostock, Institut für Chemie; } \\
\text { Universität Rostock, Institut für Chemie } \\
\text { Hellmann, Robert; Universität Rostock, Institut für Chemie } \\
\text { Bich, Eckard; Universität Rostock, Institut für Chemie }\end{array}$ \\
\hline Keywords: & $\begin{array}{l}\text { Neon ab initio pair potential, neon analytical potential function, } \\
\text { rovibrational spectra }\end{array}$ \\
\hline \multicolumn{2}{|c|}{} \\
\hline Note: PDF. You must view these files (e.g. movies) online. \\
\hline Neon1-MolPhys.tex
\end{tabular}

\section{S) ScholaroNE" \\ Manuscript Central}


Molecular Physics, Vol. 00, No. 00, DD Month 200x, 1-15

\title{
$A b$ initio potential energy curve for the neon atom pair and thermophysical properties of the dilute neon gas. \\ I. Neon-neon interatomic potential and rovibrational spectra
}

\author{
ROBERT HELLMANN, ECKARD BICH, and ECKHARD VOGEL* \\ Institut für Chemie, Universität Rostock, Albert-Einstein-Straße 3a, D-18059 Rostock, \\ Germany \\ (Received 00 Month 200x; in final form 00 Month 200x)
}

\begin{abstract}
A neon-neon interatomic potential energy curve was derived from quantum-mechanical $a b$ initio calculations using basis sets of up to t-aug-cc-pV6Z quality supplemented with bond functions and $a b$ initio methods up to $\operatorname{CCSDT}(\mathrm{Q})$. In addition, corrections for relativistc effects were determined. An analytical potential function was fitted to the $a b$ initio values and utilized to calculate the rovibrational spectra. The quality of the interatomic potential function was tested by comparison of the calculated spectra with experimental ones and those derived from other potentials of the literature. In a following paper the new interatomic potential is applied in the framework of the quantum-statistical mechanics and of the corresponding kinetic theory to determine selected thermophysical properties of neon governed by two-body and three-body interactions.
\end{abstract}

Keywords: Neon ab initio pair potential; neon analytical potential function; rovibrational spectra.

\section{Introduction}

In two recent papers $[1,2]$ we demonstrated that the pair potential between two helium atoms can be determined very accurately using standard quantum chemistry software packages and that the thermophysical two-body and three-body properties of helium gas can be calculated with uncertainties which are superior to those of experimental data. Hence, the calculated properties can be applied as standard values over the complete range of temperatures from $1 \mathrm{~K}$ to $10,000 \mathrm{~K}$.

The determination of the pair potential between two neon atoms is computationally much more demanding because of the increased number of electrons. But it could be expected that the thermophysical properties (especially transport properties) of neon, derived from a state-of-the-art pair potential, could serve as a second standard in combination with helium values for calibrating high-precision measur-

*Corresponding author. Email: eckhard.vogel@uni-rostock.de 
ing instruments at low density and as starting points within the development of transport property surface correlations.

In this work it is intended to develop an accurate $a b$ initio Ne-Ne interatomic potential based on $\operatorname{CCSD}(\mathrm{T})$ calculations using larger basis sets than previously possible and including an extrapolation to the complete basis set (CBS) limit. In addition, highly accurate corrections for neglected contributions should be included. In particular, the full $T_{3}$ operator should be taken into account by adding the differences in the interaction energies between $\operatorname{CCSDT}$ and $\operatorname{CCSD}(\mathrm{T})$, each determined with a smaller basis set, to the extrapolated $\operatorname{CCSD}(\mathrm{T})$ results. In an analogous manner corrections for perturbative quadruple excitations, core-core and core-valence correlations as well as scalar relativistic effects should be taken into account. Corrections for the breakdown of the Born-Oppenheimer approximation which had to be considered for the helium interaction potential are negligible for neon, because the neon isotopes are about five times heavier than ${ }^{4} \mathrm{He}$. To the best of our knowledge, corrections arising from the Casimir-Polder retardation [3] have not yet been calculated for neon. The retardation effect is probably very small, but should be considered in future improvements of the potential.

The second priority objective of the present paper was to calculate rovibrational energy levels which should be used to compare with experimental data as a stringent test of the interatomic pair potential. Electronic absorption spectra of the neon dimer $\mathrm{Ne}_{2}$ were investigated by Tanaka and Yoshino [4] in the vacuum ultraviolet (VUV) region with respect to the rotational structure and used to derive the potential well depth as well as the first two vibrational states and their rotational constants for the ground electronic state. Some other groups utilized the data of Tanaka and Yoshino together with high-energy beam scattering data and reliable values for different thermophysical properties of neon to determine semi-empirical potential curves for its ground electronic state from which the most recent one by Aziz and Slaman [5] is certainly the best. In 2003 Wüest and Merkt [6] performed new measurements of the transition between the $X 0_{g}^{+}$ground electronic state of $\mathrm{Ne}_{2}$ and the second electronically excited state $\mathrm{IIO}_{u}^{+}$using high-resolution VUV laser spectroscopy. They derived a map of the rovibrational energy level structure of the ground electronic state of the ${ }^{20} \mathrm{Ne}-{ }^{20} \mathrm{Ne}$ and of the ${ }^{20} \mathrm{Ne}-{ }^{22} \mathrm{Ne}$ dimers and determined a semi-empirical interaction potential for the neon dimer in its ground electronic state. The rovibrational energy levels calculated in this paper are to be compared particularly with the experimental ones by Wüest and Merkt.

\section{Towards an accurate neon-neon interaction potential energy curve}

The precise determination of the interatomic potentials between two rare gas atoms is not an easy task, whereas the demands grow with the increasing number of elec- 
trons of the respective atoms. The progress in the process of development towards an accurate neon-neon potential curve since 1999 is reported here in order to rank our work described in this paper.

In 1999 van Mourik et al. [7] derived an ab initio neon-neon potential comparably close to the semi-empirical potential curve of Aziz and Slaman [5]. The attractive part of the interaction potential is determined solely by dispersion due to electron correlation. To describe electron correlation accurately, large basis sets with many diffuse basis functions are needed. Hence van Mourik et al. [7] used for their calculations multi-augmented correlation-consistent basis sets of Dunning and coworkers up to t-aug-cc-pV5Z [8-10] and additionally a d-aug-cc-pV6Z basis set established by themselves. Suitable $a b$ initio methods for determining the electron correlation within the supermolecular approach are many-body perturbation theory and coupled-cluster (CC) theory, the latter showing very fast convergence to the full configuration interaction (Full CI) limit. In particular, CCSD(T) (coupledcluster theory with iterative singles and doubles excitations and noniterative perturbational treatment of triple excitations) [11] proved to be very successful in the calculations by van Mourik et al. [7] when using the counterpoise correction (CP) of Boys and Bernardi [12] for the basis set superposition error (BSSE) and extrapolating to the complete basis set (CBS) limit. Van Mourik et al. performed calculations in the range from $R=0.267 \mathrm{~nm}$ to $R=0.466 \mathrm{~nm}$, but reported only values for the well depth, for example, $40.92 \mathrm{~K}$ at $R=0.310 \mathrm{~nm}$ for the CBS limit with d-aug-cc-pVXZ basis sets to be compared with $42.25 \mathrm{~K}$ at $R=0.3091 \mathrm{~nm}$ for the potential by Aziz and Slaman [5]. In addition, van Mourik et al. investigated the core-core and core-valence correlation effects at the equilibrium distance and found them to be comparably small.

Van de Bovenkamp and van Duijneveldt [13] performed, also in 1999, CCSD(T) calculations with an interaction optimized basis set (IO240) including mid-bond functions $(3 \mathrm{~s} 3 \mathrm{p} 2 \mathrm{~d} 1 \mathrm{f} 1 \mathrm{~g})$. They calculated the Ne-Ne interaction potential at internuclear separations between $R=0.212 \mathrm{~nm}$ and $R=0.476 \mathrm{~nm}$ and obtained a well depth of $40.99 \mathrm{~K}$ at $R=0.310 \mathrm{~nm}$. Van de Bovenkamp and van Duijneveldt estimated that the missing attraction in their own potential compared with Aziz and Slaman should be due to basis set incompleteness, to incomplete consideration of triple and higher excitations, and to relativistic effects. Cybulski and Toczylowski [14] used $\operatorname{CCSD}(\mathrm{T})$ together with the aug-cc-pV5Z basis set and a set of mid-bond functions (3s $3 \mathrm{p} 2 \mathrm{~d} 2 \mathrm{f} 1 \mathrm{~g}$ ) for their calculations of the potential energy curve in the range between $R=0.225 \mathrm{~nm}$ and $R=0.500 \mathrm{~nm}$ and determined a well depth of $41.19 \mathrm{~K}$ at $R=0.30988 \mathrm{~nm}$ (the fitted potential has a well depth of $41.15 \mathrm{~K}$ ) which is also smaller than that of the semi-empirical potential of Aziz and Slaman [5]. Van de Bovenkamp and van Duijneveldt as well as Cybulski and Toczylowski used the counterpoise procedure for the BSSE, but did not perform 
any extrapolation to the CBS limit and did not consider core-core and core-valence contributions. However, they proved the importance of the use of bond functions. Here caution is needed if bond functions are used with small atom-centred basis sets, since they can lead to serious imbalance effects as was shown for the Ne-Ne potential by Grochola et al. [15]. Fortunately, computational advances allow to use comparably large basis sets today for $\mathrm{Ne}-\mathrm{Ne}$ so that imbalance effects can be avoided.

Gdanitz [16] applied the results of Cybulski and Toczylowski and added basic corrections for basis set incompleteness, for Full CI, for core-core and core-valence correlation as well as for scalar relativistic effects resulting in a well depth of $41.535 \mathrm{~K}$ at $R=0.31007 \mathrm{~nm}$. No analytical potential function was given in this paper. A potential fit was done later by Venkatraj et al. [17] and used in molecular dynamics simulations of gaseous and liquid neon [17] and in Monte Carlo simulations of the vapor-liquid equilibria [18]. Giese et al. [19] extended the calculations of Cybulski and Toczylowski to a larger number of internuclear separations (100 distances) and performed separate fits for the repulsive (SCF) part of the potential and for the attractive (correlation) part, whereas the fit of Cybulski and Toczylowski for the whole potential was left unchanged. Nasrabad et al. [20] extrapolated the results of Cybulski and Toczylowski to the complete basis set limit. The resulting potential has a well depth of $41.35 \mathrm{~K}$ at $R=0.3097 \mathrm{~nm}$. It was used together with a nonadditive three-body contribution for Monte Carlo simulations of the vapor-liquid equilibria. Lee [21] carried out CCSDT [22] calculations at $R=0.31 \mathrm{~nm}$ and added the difference between $\operatorname{CCSDT}$ und $\operatorname{CCSD}(\mathrm{T})$ to the $\operatorname{CCSD}(\mathrm{T})$ result of $41.19 \mathrm{~K}$ from Cybulski and Toczylowski to estimate the binding energy of the dimer. He found a well depth of $41.87 \mathrm{~K}$ which shows that missing triple contributions in $\operatorname{CCSD}(\mathrm{T})$ are the main reason for the disagreement between $\operatorname{CCSD}(\mathrm{T})$ potentials and the potential of Aziz and Slaman.

\section{Quantum chemical determination and analytical representation of the Ne-Ne potential}

The interaction energies were determined for 32 different Ne-Ne distances between $R=0.14 \mathrm{~nm}$ and $R=0.80 \mathrm{~nm}$ which is sufficient for the fit of an analytical potential function. All calculations were performed using the supermolecular approach including a full counterpoise correction [12] as follows:

$$
V(R)=\Delta E_{\mathrm{Ne}-\mathrm{Ne}}(R)=E_{\mathrm{Ne}-\mathrm{Ne}}(R)-2 E_{\mathrm{Ne}-\mathrm{Q}}(R)
$$

Here $E_{\mathrm{Ne}-\mathrm{Q}}(R)$ corresponds to the energy of a neon atom with a ghost basis set at the distance $R$.

First, $\operatorname{CCSD}(\mathrm{T})$ calculations were performed within the frozen-core approxima- 
tion using the t-aug-cc-pV5Z and t-aug-cc-pV6Z basis sets, each supplemented by a $(4 \mathrm{~s} 4 \mathrm{p} 3 \mathrm{~d} 3 \mathrm{f} 2 \mathrm{~g})$ set of bond functions centred between the two atoms. The bond function exponents are: $s p: 0.06,0.18,0.54,1.62 ; d f: 0.15,0.45,1.35 ; g: 0.3,0.9$. These basis sets (and in an analogous manner all further basis sets) are abbreviated as taV5Z+(44332) and taV6Z+(44332). For each separation $R$ the correlation part of the $\operatorname{CCSD}(\mathrm{T})$ interaction energies $V_{\mathrm{CCSD}}(\mathrm{T})$ corr obtained with these two basis sets was extrapolated to the CBS limit with the formula proposed by Halkier et al. [23]:

$$
V_{\mathrm{CCSD}(\mathrm{T}) \text { corr }}^{\mathrm{taV} X Z}=V_{\mathrm{CCSD}(\mathrm{T}) \text { corr }}^{\mathrm{CBS}}+\alpha X^{-3}
$$

The SCF interaction energies were not extrapolated and taken from the taV6Z+(44332) calculations.

Corrections for missing core-core and core-valence correlation, relativistic effects as well as for higher coupled-cluster contributions were added to the $\operatorname{CCSD}(\mathrm{T})$ interaction energies:

$$
V=V_{\mathrm{CCSD}(\mathrm{T})}^{\mathrm{CBS}}+\Delta V_{\text {core }}+\Delta V_{\text {rel }}+\Delta V_{\mathrm{T}-(\mathrm{T})}+\Delta V_{(\mathrm{Q})}
$$

The correction for core-core and core-valence correlation $\Delta V_{\text {core }}$ was estimated using the dawCV5Z basis set [24] by computing the differences between the interaction energies at the all-electron $\operatorname{CCSD}(\mathrm{T})$ level and at the frozen-core $\operatorname{CCSD}(\mathrm{T})$ level. The effect is relatively small at the equilibrium distance $(+0.068 \mathrm{~K}$ at $R=$ $0.31 \mathrm{~nm})$, but becomes rather large at small distances $(-110.5 \mathrm{~K}$ at $R=0.14 \mathrm{~nm})$.

The correction for scalar relativistic effects $\Delta V_{\text {rel }}$ was also computed at the allelectron $\operatorname{CCSD}(\mathrm{T}) /$ dawCV5Z level within the so-called Cowan-Griffin approximation [25]. The resulting correction is negative for all distances and similar in magnitude to $\Delta V_{\text {core }}$.

Missing triple contributions in the $\operatorname{CCSD}(\mathrm{T})$ calculations were estimated using a daVQZ+(3321) basis set (exponents of the bond functions: $s p: 0.1,0.3,0.9 ; d: 0.25$, $0.75 ; f: 0.45)$ in the non-relativistic frozen-core approximation by calculating the differences between the interaction energies at the $\operatorname{CCSDT}$ and $\operatorname{CCSD}(\mathrm{T})$ levels of theory. The resulting correction $\Delta V_{\mathrm{T}-(\mathrm{T})}$ is much larger than $\Delta V_{\text {core }}$ and $\Delta V_{\text {rel }}$ at equilibrium distance $(-0.646 \mathrm{~K}$ at $R=0.31 \mathrm{~nm})$ and relatively unimportant at small distances $(-8.57 \mathrm{~K}$ at $R=0.14 \mathrm{~nm})$.

The correction $\Delta V_{(\mathrm{Q})}$ resulting from the noniterative perturbational treatment of connected quadruple excitations was determined in a similar way as $\Delta V_{\mathrm{T}-(\mathrm{T})}$. The differences between the $\operatorname{CCSDT}(\mathrm{Q})[26]$ and CCSDT interaction energies were calculated with an aVTZ $+(3321)$ basis set (exponents of the bond functions equal to the ones used for the triples contribution correction). At large $R$, numerical inaccuracies turned out to be problematic. Hence the results for distances between 
$R=0.38 \mathrm{~nm}$ and $R=0.50 \mathrm{~nm}$ had to be smoothed with a polynomial, whereas the results for distances larger than $R=0.50 \mathrm{~nm}$ were extrapolated by assuming that the ratio between this correction and the total correlation interaction energy is constant. The correction $\Delta V_{(\mathrm{Q})}$ is very small and amounts to only $-0.091 \mathrm{~K}$ at $R=0.31 \mathrm{~nm}$ which shows that $\operatorname{CCSDT}(\mathrm{Q})$ is very close to the Full CI limit and that CCSDT is a good approximation to Full CI for the calculation of interaction energies.

All $a b$ initio results are given in Tables 1 and 2. The $\operatorname{CCSD}(\mathrm{T})$ calculations were performed with PSI3 [27] and with the Mainz-Austin-Budapest version of ACES II [28] which was also used for the CCSDT computations and for the determination of the relativistic corrections. The $\operatorname{CCSDT}(\mathrm{Q})$ calculations were carried out using the general coupled-cluster code MRCC of Kállay [29].

A modification of the potential function given by Tang and Toennies [30] was fitted to the $a b$ initio interaction energies:

$$
\begin{aligned}
V(R) & =A \exp \left(a_{1} R+a_{2} R^{2}+a_{-1} R^{-1}+a_{-2} R^{-2}\right) \\
& -\sum_{n=3}^{8} \frac{C_{2 n}}{R^{2 n}}\left[1-\exp (-b R) \sum_{k=0}^{2 n} \frac{(b R)^{k}}{k !}\right]
\end{aligned}
$$

The coefficients $A, a_{1}, a_{2}, a_{-1}, a_{-2}, b$ as well as the dispersion coefficients $C_{6}, C_{8}$, and $C_{10}$ were fitted independently. The higher dispersion coefficients were simultaneously determined within the fit using the recursion formula [30]:

$$
C_{2 n}=C_{2 n-6}\left(\frac{C_{2 n-2}}{C_{2 n-4}}\right)^{3}, \quad n \geq 6
$$

Deviations between calculated and fitted potential energies are smaller than $\pm 0.1 \%$ for all distances except for $R=0.80 \mathrm{~nm}$, where the difference is slightly larger. The fitted dispersion coefficients $C_{6}, C_{8}$, and $C_{10}$ are in very good agreement with the $a b$ initio dispersion coefficients derived by Thakkar et al. [31] using many-body perturbation theory. The resulting potential function has a well depth of $42.153 \mathrm{~K}$ at a distance of $R=0.30895 \mathrm{~nm}$. This comes very close to the corresponding values of the potential of Aziz and Slaman [5] with a well depth of $42.25 \mathrm{~K}$ at a distance of $R=0.3091 \mathrm{~nm}$. The potential parameters are listed in Table 3 .

\section{Vibrational and rotational energy levels}

A very direct and stringent test of any potential energy curve consists in the calculation of the energy differences for the rovibrational transitions in the ground electronic state. For that purpose the program LEVEL 7.7 by Le Roy [32] was used. The results for the ${ }^{20} \mathrm{Ne}-{ }^{20} \mathrm{Ne}$ and the ${ }^{20} \mathrm{Ne}^{22} \mathrm{Ne}$ dimers calculated for the potential energy curves of Aziz and Slaman [5], of Cybulski and Toczylowski [14], 
of Wüest and Merkt [6] as well as of the present paper are listed in Table 4 and Table 5. In general, three vibrational states were found for both dimers, whereas the energy of each ground vibrational state $v=0$ is only at about $60 \%$ of the dissociation energy $\left(-D_{\mathrm{e}}=-42.153 \mathrm{~K}\right)$ characterizing the weakly bound nature of the potential. The energies for the rotationally excited states differ from that of the $J=0$ states by the addition of the centrifugal potential. Only the bound states with negative energies $E_{v J}$ are accessible with the experimental arrangement by Wüest and Merkt [6], whereas the lifetimes for the quasibound levels with positive energies are too short.

As shown in Table 4, Wüest and Merkt [6] observed actually nine of the ten bound rovibrational levels of the ${ }^{20} \mathrm{Ne}^{-20} \mathrm{Ne}$ dimer. The energy differences calculated for the potential of Wüest and Merkt agree of course with the observed values of these authors within the uncertainties of the spectra (numbers in brackets in the third column of the table), since the potential energy curve was derived on the basis of these observed data. The deviations between the energy differences calculated with the new potential of this paper and the observed values for $v=0$ increase with increasing $J$ and exceed the experimental uncertainties for higher $J$. On the contrary, the deviations between the values for the new potential and the observed data for $v=1$ are in reasonable agreement because of the ten times higher experimental uncertainties. The same findings result from a comparison of the values calculated for the semi-empirical potential by Aziz and Slaman [5] and of the observed data by Wüest and Merkt [6]. In addition, the values calculated for the potentials of Aziz and Slaman and of the present paper agree with each other better than with the observed data for $v=0$. Finally, the values determined from the potential by Cybulski and Toczylowski [14] show comparably large deviations from the experimentally observed data.

Table 5 illustrates that the spectra of the ${ }^{20} \mathrm{Ne}^{-22} \mathrm{Ne}$ dimer are of poorer quality and characterized by larger experimental uncertainties. Hence, only five of altogether 18 bound rovibrational levels were found by Wüest and Merkt [6]. Furthermore, the values calculated for all four considered potentials agree within the experimental uncertainties with the observed data.

In Table 6 the dissociation energy $D_{\mathrm{e}}$, the equilibrium internuclear distance $R_{\varepsilon}$, the vibrational-ground-state dissociation energy $D_{00}$, and the vibrational interval $\Delta G_{1 / 2}$ of the ${ }^{20} \mathrm{Ne}-{ }^{20} \mathrm{Ne}$ dimer in the ground electronic state are compared for the considered potential energy curves including that of Gdanitz [16]. The table makes evident that the semi-empirical potential by Aziz and Slaman fitted primarily to different experimental data, the potential by Wüest and Merkt [6] adjusted to their rovibrational spectra, and the potential of this paper derived from quantummechanical ab initio calculations are in close agreement. 


\section{$5 \quad$ Summary and conclusions}

The interaction energies for the neon atom pair were calculated for a large number of interatomic separations. Basis sets of up to t-aug-cc-pV6Z quality with bond functions at the $\operatorname{CCSD}(\mathrm{T})$ level were utilized. In addition, highly accurate corrections for higher-order coupled-cluster excitations up to $\operatorname{CCSDT}(\mathrm{Q})$ as well as corrections for core-core and core-valence correlations and for scalar relativistic effects were determined. It could be shown that, when going from $\operatorname{CCSD}(\mathrm{T})$ to CCSDT, the well depth increases considerably, whereas a further enhancement to $\operatorname{CCSDT}(\mathrm{Q})$ has only a marginal effect.

An analytical potential function was fitted to the ab initio values and used to derive the rovibrational spectra of the ${ }^{20} \mathrm{Ne}^{20} \mathrm{Ne}$ and ${ }^{20} \mathrm{Ne}-{ }^{22} \mathrm{Ne}$ dimers in the ground electronic state. These values were compared with highly accurate experimental data of Wüest and Merkt [6] and with values calculated for other potential energy curves from the literature. The comparison makes evident that the potentials of Aziz and Slaman [5], of Wüest and Merkt [6], and of the present paper are in close agreement. One should keep in mind that the rovibrational spectra are essentially governed by the attractive part of the potential around its minimum. Hence a comprehensive comparison with experimental data for the transport properties, which are strongly influenced by the repulsive part of the potential, represents a further stringent test and will become the focus of the second paper of this series [33]. 


\section{References}

[1] R. Hellmann, E. Bich, and E. Vogel, Mol. Phys., submitted.

[2] E. Bich, R. Hellmann, and E. Vogel, Mol. Phys., submitted.

[3] H. B. G. Casimir and D. Polder, Phys. Rev., 73, 360 (1948).

[4] Y. Tanaka and K. Yoshino, J. Chem. Phys., 57, 2964 (1972).

[5] R. A. Aziz and M. J. Slaman, Chem. Phys., 130, 187 (1989).

[6] A. Wüest and F. Merkt, J. Chem. Phys., 118, 8807 (2003).

[7] T. van Mourik, A. K. Wilson, and T. H. Dunning, Jr., Mol. Phys., 96, 529 (1999).

[8] T. H. Dunning, Jr., J. Chem. Phys., 90, 1007 (1989).

[9] R. A. Kendall, T. H. Dunning, Jr., and R. J. Harrison, J. Chem. Phys., 96, 6796 (1992).

[10] D. E. Woon and T. H. Dunning, Jr., J. Chem. Phys., 100, 2975 (1994).

[11] K. Raghavachari, G. W. Trucks, J. A. Pople, and M. Head-Gordon, Chem. Phys. Lett., 157, 479 (1989).

[12] S. F. Boys and F. Bernardi, Mol. Phys., 19, 553 (1970).

[13] J. van de Bovenkamp and F. B. van Duijneveldt, Chem. Phys. Lett., 309, 287 (1999).

[14] S. M. Cybulski and R. R. Toczylowski, J. Chem. Phys., 111, 10520 (1999).

[15] G. Grochola, T. Petersen, S. P. Russo, and I. K. Snook, Mol. Phys., 100, 3867 (2002).

[16] R. J. Gdanitz, Chem. Phys. Lett., 348, 67 (2001).

[17] M. Venkatraj, M. G. Müller, H. Huber and R. J. Gdanitz, Collect. Czech. Chem. Commun., 68, 627 (2003).

[18] M. Venkatraj, C. Bratschi, H. Huber, and R. J. Gdanitz, Fluid Phase Eq., 218, 285 (2004).

[19] T. J. Giese, V. M. Audette, and D. M. York, J. Chem. Phys., 119, 2618 (2003).

[20] A. E. Nasrabad, R. Laghaei, and U. K. Deiters, J. Chem. Phys., 121, 6423 (2004).

[21] J. S. Lee, Theor. Chem. Acc., 113, 87 (2005).

[22] J. Noga and R. J. Bartlett, J. Chem. Phys., 86, 7041 (1987), Erratum J. Chem. Phys., 89, 3401 (1988).

[23] A. Halkier, T. Helgaker, P. Jørgensen, W. Klopper, H. Koch, J. Olsen, and A. K. Wilson, Chem. Phys. Lett., 286, 243 (1998).

[24] K. A. Peterson and T. H. Dunning, Jr., J. Chem. Phys., 117, 10548 (2002).

[25] R. D. Cowan and D. C. Griffin, J. Opt. Soc. Am., 66, 1010 (1976).

[26] M. Kállay and J. Gauss, J. Chem. Phys., 123, 214105 (2005).

[27] "PSI3: An Open-Source Ab Initio Electronic Structure Package", T. D. Crawford, C. D. Sherrill, E. F. Valeev, J. T. Fermann, R. A. King, M. L. Leininger, S. T. Brown, C. L. Janssen, E. T. Seidl, J. P. Kenny, and W. D. Allen, J. Comp. Chem., 28, 1610 (2007).

[28] J. F. Stanton, J. Gauss, J. D. Watts, P. G. Szalay, and R. J. Bartlett, with contributions from A. A. Auer, D. B. Bernholdt, O. Christiansen, M. E. Harding, M. Heckert, O. Heun, C. Huber, D. Jonsson, J. Jusélius, W. J. Lauderdale, T. Metzroth, C. Michauk, D. R. Price, K. Ruud, F. Schiffmann, A. Tajti, M. E. Varner, J. Vázquez, and the integral packages: MOLECULE (J. Almlöf and P. R. Taylor), PROPS (P. R. Taylor), and ABACUS (T. Helgaker, H. J. Aa. Jensen, P. Jørgensen, and J. Olsen). See, also J. F. Stanton, J. Gauss, J. D. Watts, W. J. Lauderdale, and R. J. Bartlett, Int. J. Quantum Chem. Symp., 26, 879 (1992). Current version see http://www.aces2.de.

[29] MRCC, a string-based general coupled cluster program suite written by M. Kállay. See also M. Kállay and P. R. Surján, J. Chem. Phys., 115, 2945 (2001) as well as: http://www.mrcc.hu.

[30] K. T. Tang and J. P. Toennies, J. Chem. Phys., 80, 3726 (1984).

[31] A. J. Thakkar, H. Hettema, and P. E. S. Wormer, J. Chem. Phys., 97, 3252 (1992).

[32] R. J. Le Roy, Level 7.7: A Computer Program for Solving the Radial Schrödinger Equation for Bound and Quasibound Levels, University of Waterloo, Chemical Physics Research Report No. CP-661, Waterloo, Ontario, Canada.

[33] E. Bich, R. Hellmann, and E. Vogel, in preparation. 
10

Table 1. Ne-Ne SCF and CCSD(T) interaction energies for the taV5Z+(44332) and taV6Z+(44332) basis sets and the extrapolated $\operatorname{CCSD}(\mathrm{T})$ values. All energies are in Kelvin.

\begin{tabular}{|c|c|c|c|c|c|}
\hline \multirow[t]{2}{*}{$R / \mathrm{nm}$} & \multicolumn{2}{|c|}{$\mathrm{V}(\mathrm{SCF})$} & \multicolumn{3}{|c|}{$\mathrm{V}(\mathrm{CCSD}(\mathrm{T}))$} \\
\hline & taV5Z+(44332) & taV6Z+(44332) & taV5Z+(44332) & $\operatorname{taV} 6 Z+(44332)$ & extrapolated \\
\hline 0.14 & 71550.433 & 71548.487 & 69122.802 & 69044.386 & 68939.345 \\
\hline 0.16 & 28504.771 & 28503.861 & 27107.732 & 27067.581 & 27013.678 \\
\hline 0.18 & 11385.933 & 11385.622 & 10504.957 & 10486.497 & 10461.566 \\
\hline 0.20 & 4551.060 & 4550.932 & 3966.717 & 3957.967 & 3946.125 \\
\hline 0.22 & 1817.497 & 1817.446 & 1421.412 & 1417.452 & 1412.082 \\
\hline 0.24 & 724.521 & 724.515 & 454.750 & 453.070 & 450.770 \\
\hline 0.25 & 457.077 & 457.078 & 234.567 & 233.499 & 232.029 \\
\hline 0.26 & 288.193 & 288.196 & 104.787 & 104.124 & 103.208 \\
\hline 0.27 & 181.605 & 181.610 & 30.507 & 30.110 & 29.559 \\
\hline 0.28 & 114.373 & 114.379 & -10.086 & -10.314 & -10.634 \\
\hline 0.29 & 71.991 & 71.997 & -30.554 & -30.678 & -30.855 \\
\hline 0.30 & 45.290 & 45.295 & -39.279 & -39.328 & -39.401 \\
\hline 0.31 & 28.478 & 28.481 & -41.357 & -41.362 & -41.375 \\
\hline 0.32 & 17.897 & 17.900 & -39.870 & -39.855 & -39.840 \\
\hline 0.33 & 11.241 & 11.245 & -36.658 & -36.626 & -36.587 \\
\hline 0.34 & 7.057 & 7.060 & -32.765 & -32.726 & -32.678 \\
\hline 0.35 & 4.428 & 4.431 & -28.773 & -28.737 & -28.690 \\
\hline 0.36 & 2.778 & 2.780 & -25.000 & -24.962 & -24.913 \\
\hline 0.37 & 1.741 & 1.743 & -21.576 & -21.542 & -21.497 \\
\hline 0.38 & 1.092 & 1.093 & -18.555 & -18.523 & -18.481 \\
\hline 0.40 & 0.428 & 0.429 & -13.673 & -13.651 & -13.623 \\
\hline 0.42 & 0.167 & 0.168 & -10.114 & -10.094 & -10.068 \\
\hline 0.44 & 0.065 & 0.066 & -7.542 & -7.526 & -7.505 \\
\hline 0.46 & 0.026 & 0.026 & -5.684 & -5.671 & -5.654 \\
\hline 0.48 & 0.010 & 0.010 & -4.329 & -4.323 & -4.314 \\
\hline 0.50 & 0.004 & 0.004 & -3.338 & -3.333 & -3.325 \\
\hline 0.52 & 0.002 & 0.002 & -2.603 & -2.597 & -2.589 \\
\hline 0.56 & 0.000 & 0.000 & -1.629 & -1.626 & -1.621 \\
\hline 0.60 & 0.000 & 0.000 & -1.056 & -1.055 & -1.052 \\
\hline 0.65 & 0.000 & 0.000 & -0.641 & -0.640 & -0.639 \\
\hline 0.70 & 0.000 & 0.000 & -0.405 & -0.405 & -0.404 \\
\hline 0.80 & 0.000 & 0.000 & -0.178 & -0.178 & -0.178 \\
\hline
\end{tabular}




\section{Page 11 of 15 \\ Molecular Physics}

Table 2. Corrections to the extrapolated $\operatorname{CCSD}(\mathrm{T})$ interaction energies and the final potential values. All energies are in Kelvin.

\begin{tabular}{|c|c|c|c|c|c|}
\hline$R / \mathrm{nm}$ & $\begin{array}{c}\Delta V_{\text {core }} \\
\text { dawCV } 5 \mathrm{Z}\end{array}$ & $\begin{array}{c}\Delta V_{\text {rel }} \\
\text { dawCV } 5 \mathrm{Z}\end{array}$ & $\begin{array}{c}\Delta V_{\mathrm{T}-(\mathrm{T})} \\
\mathrm{daVQZ}+(3321)\end{array}$ & $\begin{array}{c}\Delta V_{(\mathrm{Q})} \\
\mathrm{aVTZ}+(3321)\end{array}$ & $V(R)$ \\
\hline 0.14 & -110.504 & -197.556 & -8.572 & 11.597 & 68634.310 \\
\hline 0.16 & -52.833 & -77.901 & -7.131 & 4.128 & 26879.940 \\
\hline 0.18 & -24.471 & -29.825 & -5.560 & 0.453 & 10402.164 \\
\hline 0.20 & -10.933 & -11.126 & -4.124 & -0.964 & 3918.978 \\
\hline 0.22 & -4.647 & -4.074 & -2.975 & -1.159 & 1399.226 \\
\hline 0.24 & -1.827 & -1.487 & -2.124 & -0.888 & 444.443 \\
\hline 0.25 & -1.093 & -0.906 & -1.793 & -0.747 & 227.490 \\
\hline 0.26 & -0.620 & -0.561 & -1.513 & -0.558 & 99.956 \\
\hline 0.27 & -0.321 & -0.356 & -1.277 & -0.420 & 27.186 \\
\hline 0.28 & -0.136 & -0.234 & -1.077 & -0.307 & -12.388 \\
\hline 0.29 & -0.026 & -0.161 & -0.908 & -0.215 & -32.165 \\
\hline 0.30 & 0.036 & -0.116 & -0.766 & -0.145 & -40.392 \\
\hline 0.31 & 0.068 & -0.087 & -0.646 & -0.091 & -42.130 \\
\hline 0.32 & 0.082 & -0.069 & -0.544 & -0.052 & -40.423 \\
\hline 0.33 & 0.086 & -0.056 & -0.459 & -0.024 & -37.040 \\
\hline 0.34 & 0.082 & -0.046 & -0.387 & -0.002 & -33.032 \\
\hline 0.35 & 0.076 & -0.039 & -0.327 & 0.008 & -28.972 \\
\hline 0.36 & 0.069 & -0.033 & -0.277 & 0.017 & -25.137 \\
\hline 0.37 & 0.061 & -0.029 & -0.234 & 0.021 & -21.678 \\
\hline 0.38 & 0.053 & -0.025 & -0.199 & 0.022 & -18.629 \\
\hline 0.40 & 0.040 & -0.019 & -0.144 & 0.023 & -13.723 \\
\hline 0.42 & 0.030 & -0.014 & -0.105 & 0.020 & -10.136 \\
\hline 0.44 & 0.023 & -0.011 & -0.078 & 0.017 & -7.554 \\
\hline 0.46 & 0.017 & -0.008 & -0.058 & 0.014 & -5.690 \\
\hline 0.48 & 0.013 & -0.006 & -0.044 & 0.011 & -4.340 \\
\hline 0.50 & 0.010 & -0.005 & -0.034 & 0.009 & -3.345 \\
\hline 0.52 & 0.008 & -0.004 & -0.026 & 0.007 & -2.605 \\
\hline 0.56 & 0.005 & -0.002 & -0.016 & 0.004 & -1.631 \\
\hline 0.60 & 0.003 & -0.002 & -0.010 & 0.003 & -1.058 \\
\hline 0.65 & 0.002 & -0.001 & -0.006 & 0.002 & -0.643 \\
\hline 0.70 & 0.001 & -0.001 & -0.004 & 0.001 & -0.406 \\
\hline 0.80 & 0.001 & 0.000 & -0.002 & 0.000 & -0.179 \\
\hline
\end{tabular}


Table 3. Potential parameters

1

2

3

4

5

7

8

9

10

11

12

13

14

15

16

17

18

19

20

21

22

23

24

25

26

27

28

29

30

31

32

33

34

35

36

37

38

39

40

41

42

43

44

45

46

47

48

49

50

51

52

53

54

55

56

57

58

59

60

\begin{tabular}{llll}
\hline Parameter & Unit & Value & Thakkar et al. [31] \\
\hline$A$ & $\mathrm{~K}$ & $4.02915058383 \times 10^{7}$ & \\
$a_{1}$ & $(\mathrm{~nm})^{-1}$ & $-4.28654039586 \times 10^{1}$ & \\
$a_{2}$ & $(\mathrm{~nm})^{-2}$ & -3.33818674327 & \\
$a_{-1}$ & $\mathrm{~nm}$ & $-5.34644860719 \times 10^{-2}$ & \\
$a_{-2}$ & $(\mathrm{~nm})^{2}$ & $5.01774999419 \times 10^{-3}$ & \\
$b$ & $(\mathrm{~nm})^{-1}$ & $4.92438731676 \times 10^{1}$ & \\
$C_{6}$ & $\mathrm{~K}(\mathrm{~nm})^{6}$ & $4.40676750157 \times 10^{-2}$ & $4.54364 \times 10^{-2}$ \\
$C_{8}$ & $\mathrm{~K}(\mathrm{~nm})^{8}$ & $1.64892507701 \times 10^{-3}$ & $1.75423 \times 10^{-3}$ \\
$C_{10}$ & $\mathrm{~K}(\mathrm{~nm})^{10}$ & $7.90473640524 \times 10^{-5}$ & $8.34962 \times 10^{-5}$ \\
$C_{12}$ & $\mathrm{~K}(\mathrm{~nm})^{12}$ & $4.85489170103 \times 10^{-6}$ & \\
$C_{14}$ & $\mathrm{~K}(\mathrm{~nm})^{14}$ & $3.82012334054 \times 10^{-7}$ & \\
$C_{16}$ & $\mathrm{~K}(\mathrm{~nm})^{16}$ & $3.85106552963 \times 10^{-8}$ & \\
\hline$\varepsilon / k_{\mathrm{B}}$ & $\mathrm{K}$ & 42.152521 & \\
$R_{\varepsilon}$ & $\mathrm{nm}$ & 0.30894556 & \\
$\sigma$ & $\mathrm{nm}$ & 0.27612487 & \\
\hline
\end{tabular}




\section{Page 13 of 15 \\ Molecular Physics}

Table 4. Energy differences between the rotational levels for the three vibrational states of the electronic ground state of the ${ }^{20} \mathrm{Ne}-{ }^{20} \mathrm{Ne}$ dimer and comparison between values calculated for different potential energy curves and the observed values by Wüest und Merkt [6]. Last column: energy calculated for the potential of the present paper to be compared with the dissociation energy: $-D_{\mathrm{e}}=-42.153 \mathrm{~K}$.

\begin{tabular}{|c|c|c|c|c|c|c|c|}
\hline \multirow[b]{3}{*}{$v$} & \multirow[b]{3}{*}{$J$} & \multirow{3}{*}{$\begin{array}{c}\text { Observed } \\
\text { Wüest, } \\
\text { Merkt }[6] \\
\frac{E_{v J}-E_{00}}{\mathrm{~cm}^{-1}}\end{array}$} & \multicolumn{4}{|c|}{ Calculated differences for the potential energy curves by } & \multirow{3}{*}{$\begin{array}{c}\text { Calculated } \\
\text { energy } \\
\text { present } \\
\frac{E_{v J}}{\mathrm{~K}}\end{array}$} \\
\hline & & & $\begin{array}{c}\text { Aziz, } \\
\text { Slaman [5] }\end{array}$ & $\begin{array}{c}\text { Cybulski, } \\
\text { Toczylowski [14] }\end{array}$ & $\begin{array}{l}\text { Wüest, } \\
\text { Merkt [6] }\end{array}$ & present & \\
\hline & & & $\frac{E_{v J}-E_{00}}{\mathrm{~cm}^{-1}}$ & $\frac{E_{v J}-E_{00}}{\mathrm{~cm}^{-1}}$ & $\frac{E_{v J}-E_{00}}{\mathrm{~cm}^{-1}}$ & $\frac{E_{v J}-E_{00}}{\mathrm{~cm}^{-1}}$ & \\
\hline 0 & 0 & 0.0 & 0.0 & 0.0 & 0.0 & 0.0 & -24.0941 \\
\hline 0 & 2 & $0.937(10)$ & 0.9333 & 0.9266 & 0.9300 & 0.9338 & -22.7506 \\
\hline 0 & 4 & $3.088(10)$ & 3.0984 & 3.0757 & 3.0875 & 3.1001 & -19.6338 \\
\hline 0 & 6 & $6.426(18)$ & 6.4630 & 6.4145 & 6.4406 & 6.4666 & -14.7901 \\
\hline 0 & 8 & $10.947(19)$ & 10.9691 & 10.8833 & 10.9319 & 10.9753 & -8.3031 \\
\hline 0 & 10 & $16.464(26)$ & 16.5159 & 16.3769 & 16.4608 & 16.5247 & -0.3187 \\
\hline 0 & 12 & & 22.8836 & 22.6512 & 22.8044 & 22.8877 & 8.8362 \\
\hline 0 & 14 & & 29.8065 & & & & \\
\hline 1 & 0 & $13.76(14)$ & 13.8443 & 13.4551 & 13.7746 & 13.7928 & -4.2494 \\
\hline 1 & 2 & $14.36(14)$ & 14.4514 & 14.0478 & 14.3756 & 14.3944 & -3.3838 \\
\hline 1 & 4 & $15.73(14)$ & 15.8174 & 15.3762 & 15.7275 & 15.7455 & -1.4398 \\
\hline 1 & 6 & & 17.7436 & 17.2201 & 17.6321 & 17.6352 & 1.2791 \\
\hline 2 & 0 & & 16.9199 & 16.2551 & 16.8146 & 16.7333 & -0.0187 \\
\hline
\end{tabular}


Table 5. Energy differences between the rotational levels for the three vibrational states of the electronic ground state of the ${ }^{20} \mathrm{Ne}^{22} \mathrm{Ne}$ dimer and comparison between values calculated for different potential energy curves and the observed values by Wüest und Merkt [6]. Last column: energy calculated for the potential of the present paper to be compared with the dissociation energy: $-D_{\mathrm{e}}=-42.153 \mathrm{~K}$.

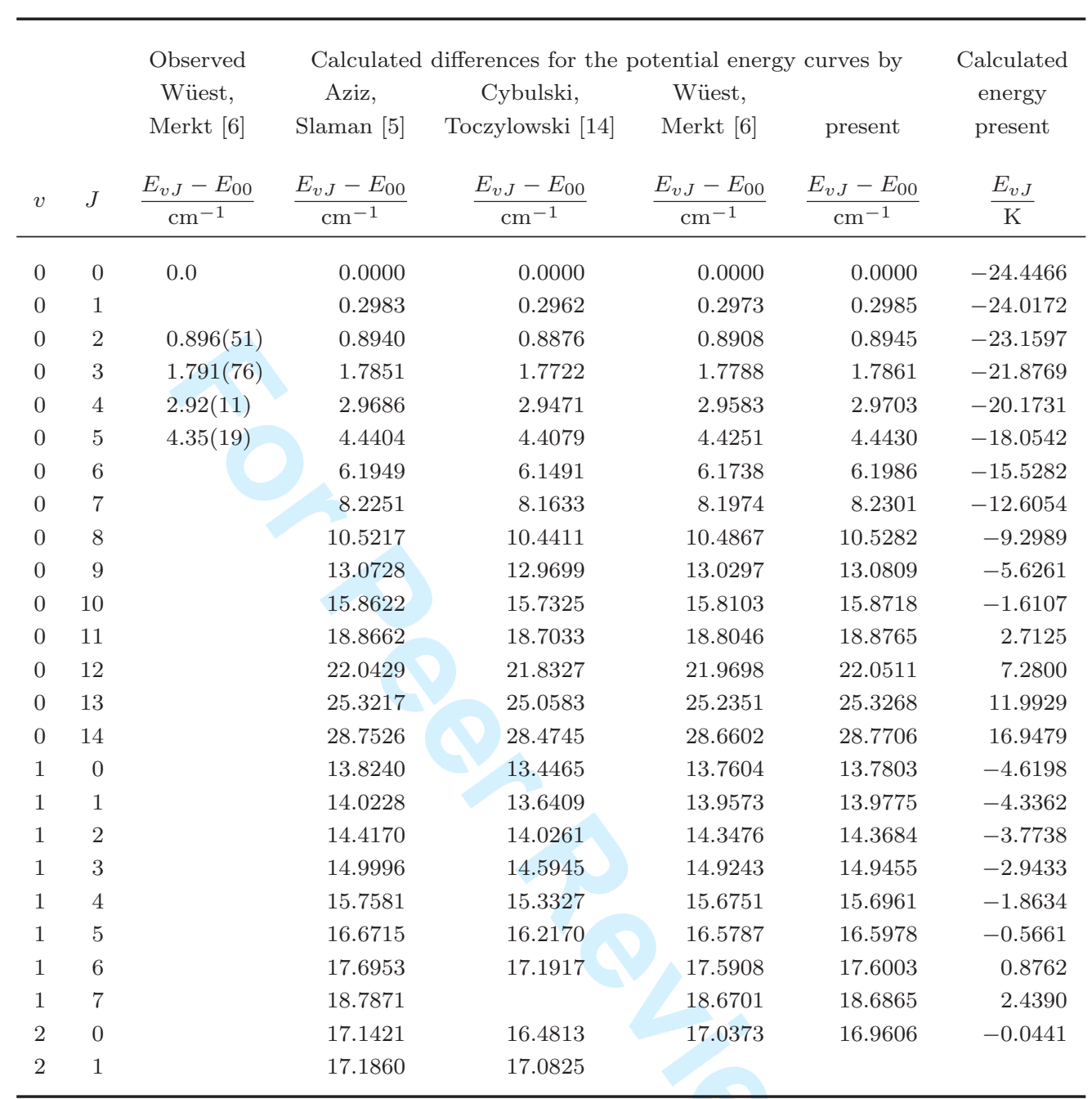


Table 6. Dissociation energy $D_{\mathrm{e}}$, equilibrium internuclear distance $R_{\varepsilon}$, vibrational-ground-state dissociation energy $D_{00}$, and vibrational interval $\Delta G_{1 / 2}$ of the ${ }^{20} \mathrm{Ne}^{20} \mathrm{Ne}$ dimer in the ground electronic state for different potential energy curves.

\begin{tabular}{ccccc}
\hline $\begin{array}{c}D_{\mathrm{e}} \\
\mathrm{K}\end{array}$ & $R_{\varepsilon}$ & $D_{00}$ & $\Delta G_{1 / 2}$ & Reference \\
& $\mathrm{nm}$ & $\mathrm{K}$ & $\mathrm{K}$ & \\
\hline 42.25 & 0.3091 & 24.07 & 19.91 & Aziz, Slaman [5] \\
41.155 & 0.30988 & 23.399 & 19.37 & Cybulski, Toczylowski [6] \\
$41.535 \pm 0.29$ & $0.31007 \pm 0.0002$ & $23.605 \pm 0.29$ & $19.592 \pm 0.14$ & Gdanitz [16] \\
$42.30 \pm 0.17$ & $0.3094 \pm 0.0001$ & 24.22 & $19.82 \pm 0.17$ & Wüest, Merkt [6] \\
42.153 & 0.30895 & 24.094 & 19.845 & present \\
\hline
\end{tabular}

1

5

6

7

8

10

11

12

13

14

15

16

17

18

19

20

21

22

23

24

25

26

27

28

29

30

31

32

33

34

35

36

37

38

39

40

41

42

43

44

45

46

47

48

49

50

51

52

53

54

55

56

57

58

59

60 